\title{
Small-Sized Flat-Tip CNT Emitters for Miniaturized X-Ray Tubes
}

\author{
Hyun Jin Kim, ${ }^{1}$ Jun Mok Ha, ${ }^{1}$ Sung Hwan Heo, ${ }^{2}$ and Sung Oh Cho ${ }^{1}$ \\ ${ }^{1}$ Department of Nuclear and Quantum Engineering, Korea Advanced Institute of Science and Technology, \\ Daejeon 305-701, Republic of Korea \\ ${ }^{2}$ Particla Co. Ltd., Daejeon 305-701, Republic of Korea
}

Correspondence should be addressed to Sung Oh Cho, socho@kaist.ac.kr

Received 18 October 2012; Accepted 7 December 2012

Academic Editor: Yue Li

Copyright ( $) 2012$ Hyun Jin Kim et al. This is an open access article distributed under the Creative Commons Attribution License, which permits unrestricted use, distribution, and reproduction in any medium, provided the original work is properly cited.

\begin{abstract}
Small tip-type CNT emitters with the diameter of $0.8 \mathrm{~mm}$ were fabricated for miniaturized X-ray tubes. The CNT emitters were prepared by dropping CNTs and silver nanoparticles on a flat surface of a W metal tip followed by annealing at $800^{\circ} \mathrm{C}$ for $2 \mathrm{~h}$ under vacuum. The CNT emitters exhibit good field emission properties with the threshold electric field of $1.15 \mathrm{~V} / \mu \mathrm{m}$ and the field enhancement factor of 12,050. CNTs were well attached to a flat W tip surface without coating on the side plane of the tip, and thus beam divergence could be minimized. Consequently, a miniaturized X-ray tube with the inner diameter of $5 \mathrm{~mm}$ was successfully demonstrated using the tip-type CNT emitter.
\end{abstract}

Nanostructured materials are widely used for electron emitters because of their good field-emission properties [1-7]. Among them, carbon nanotubes (CNTs) are mostly used as electron emitters because of their excellent electron emission property, chemical inertness, and high electrical and thermal conductivity [ $8-11]$. Recently, miniaturized X-ray tubes [1217] are being developed based on CNT emitters for the applications to brachytherapy $[12,16,17]$, a cavity-inserted $\mathrm{X}$-ray imaging $[15,18]$, nondestructive $\mathrm{X}$-ray radiography, and a compact X-ray spectrometer $[13,15]$. The diameter of miniaturized X-ray tubes is generally less than $10 \mathrm{~mm}$, and a thermionic cathode of which operating temperature should be normally higher than $1000^{\circ} \mathrm{C}$ can induce a serious heating of the small X-ray tube. High operating temperature of miniaturized X-ray tubes limits the applications of the tubes, for example, to brachytherapy. Consequently, a cooling device is required for the operation, but the cooling device increases the size of the miniaturized X-ray tube. In this sense, CNT emitters are proper electron sources because electrons are generated through field emission, and hence the cold emission process does not increase the temperature of the X-ray tube. In addition, CNT emitters are also promising electron emitters for microfocus X-ray tubes [19].
$\mathrm{X}$-ray image quality based on a microfocus X-ray tube is determined by the electron beam size of the tube. Therefore, the diameter of an electron beam source should be very small for the applications to miniaturized X-ray tubes or microfocus X-ray tubes.

Tip-shaped CNT emitters where CNTs are coated on a metal tip with the diameter less than $1 \mathrm{~mm}$ can satisfy the requirements of an electron beam source for miniaturized $\mathrm{X}$-ray tubes or microfocus X-ray tubes. A few methods have been developed to prepare such tip-shaped CNT emitters. For example, a sharp-tip CNT emitter where CNTs are coated on a sharp metal tip that is chemically etched was developed. CNTs can be coated on the sharp metal tips by chemical vapor deposition (CVD) [19-22] or electrophoresis [23]. However CNT tips fabricated by these methods have a serious weakness for a real application to X-ray tubes: weak adhesion between CNTs and the metal substrate. X-ray tubes are operated at high voltages, and electrical breakdown can occur during the operation. CNT emitters must withstand electrical breakdown for a stable operation, but the CNTs coated on a metal tip by CVD or electrophoresis tend to be easily detached when breakdown occurs [24-27]. In addition, sharp geometry also has some disadvantages for 


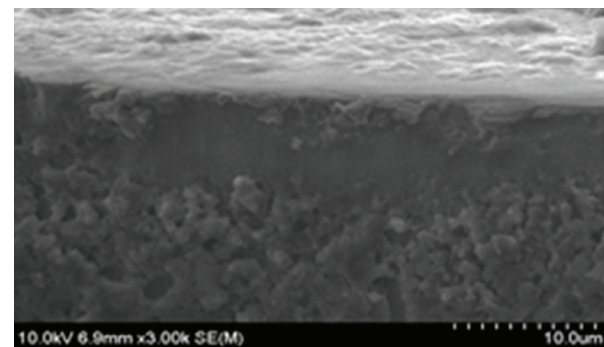

(a)

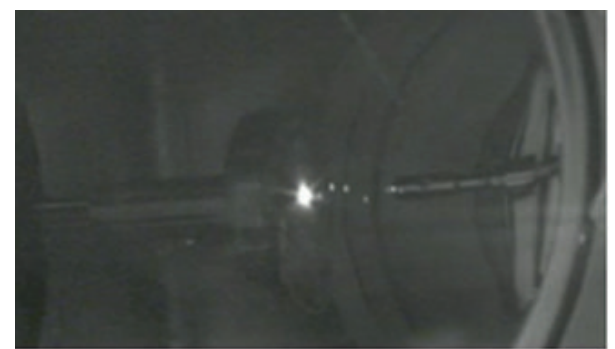

(c)

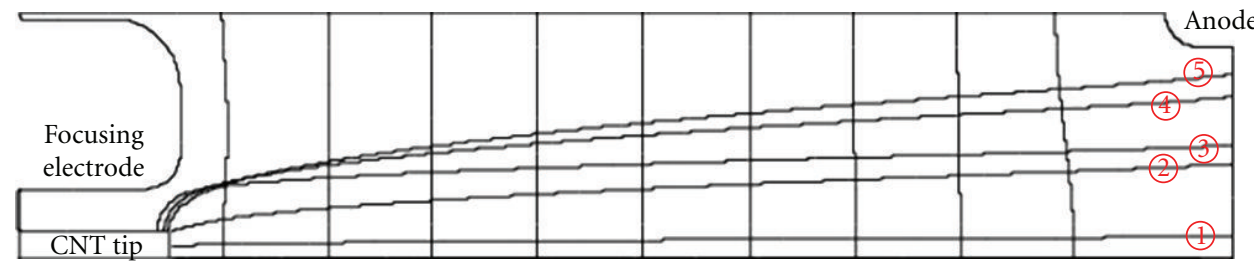

(b)

Figure 1: (a) SEM image of a flat-tip CNT emitter with CNTs coated on the side plane of a W tip. (b) Trajectories of electrons emitted at different positions of a flat-tip emitter. (c) Characterization of the electron beam diameter at the anode position using the emitter shown in (a) and a phosphorous screen.

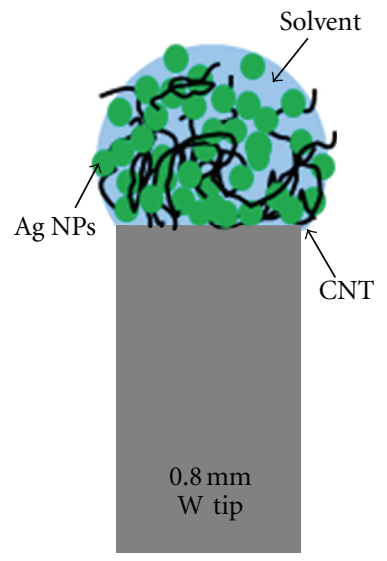

(a)

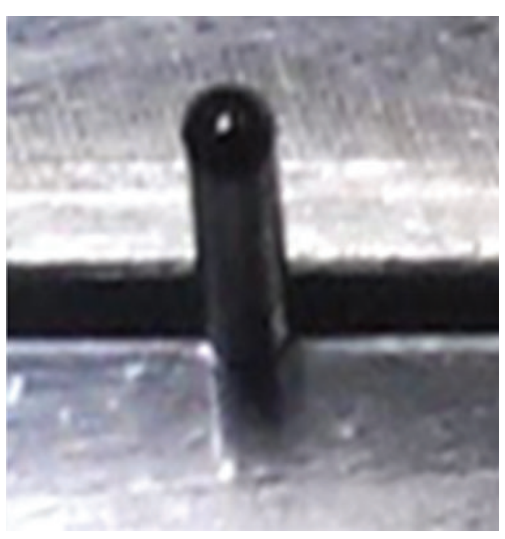

(b)

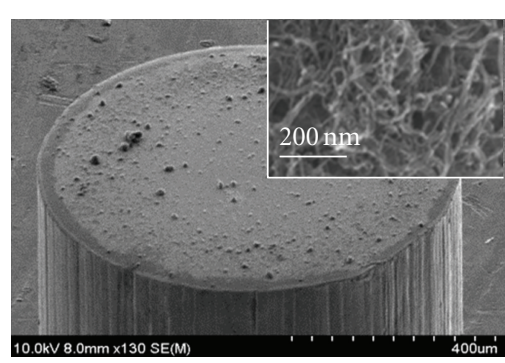

(c)

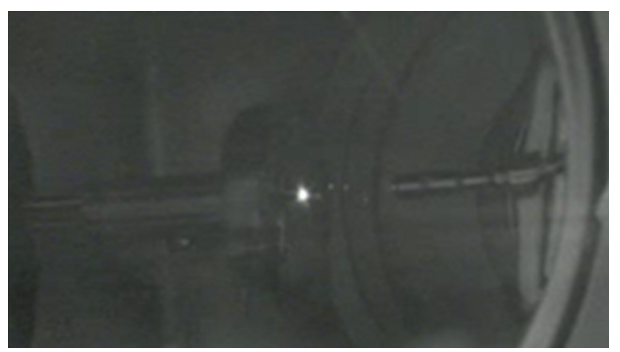

(d)

Figure 2: (a) Schematic diagram to display the fabrication process of a flat-tip CNT emitter. (b) Optical image of a CNT drop on a W tip surface. (c) SEM image of a fabricated flat-tip CNT emitter. Inset: the magnified SEM image of the surface of the emitter. (d) Characterization of the electron beam diameter at the anode position using the emitter shown in (c) and a phosphorous screen. 


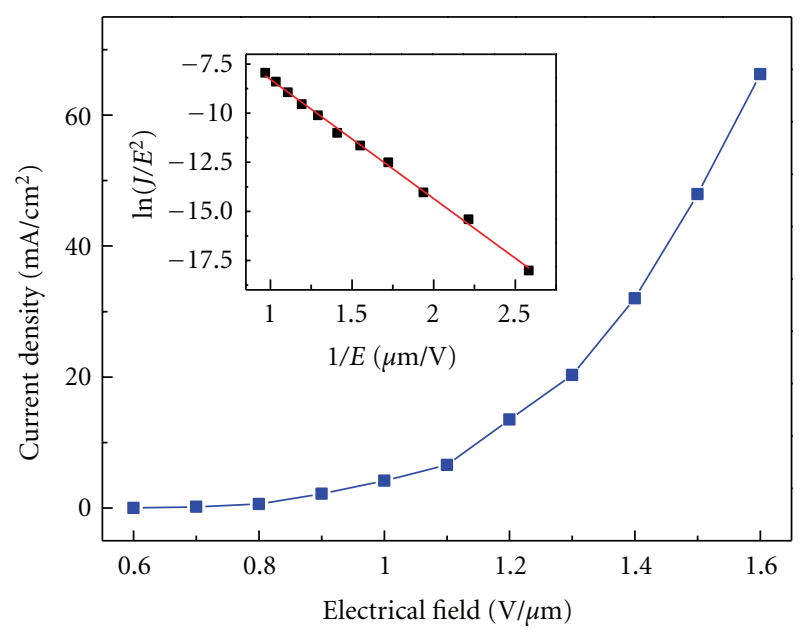

FIGURE 3: Current density-electric field profile of the fabricated flattip CNT emitter. The inset is the F-N plot of the tip.

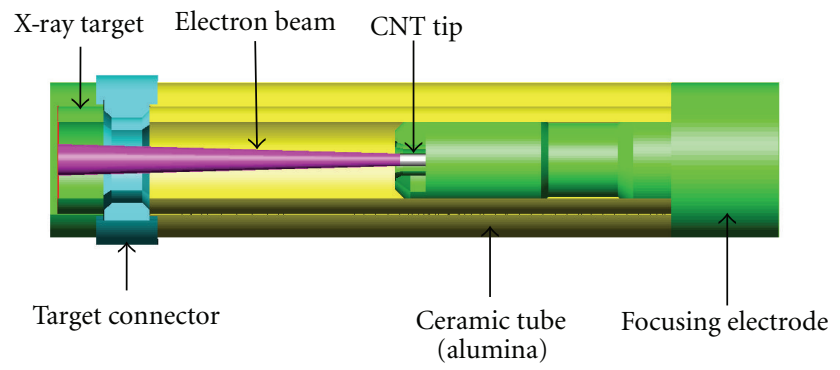

Figure 4: Schematic diagram of the miniaturized X-ray tube.

the applications to miniaturized X-ray tubes or high-power $\mathrm{X}$-ray tubes. Due to the sharp and inclined geometry, electron emission positions are different and furthermore an electron beam is diverged radially. As a result, the beam quality is not so good and a device to focus the electron beam is necessary. Furthermore, the number of useful CNTs on a sharp metal tip is limited and hence each CNT must emit a high electron current to get an enough high total beam current for the practical application to an X-ray tube. As a result, CNTs can be easily damaged by high joule heating, reducing the lifetime of the CNT emitters. To overcome these, we proposed a flat-tip CNT emitter, where CNTs were coated on a flat end surface of a metal wire with a small $(<1 \mathrm{~mm})$ diameter. The electric field at the surface of a sharp-tip emitter is radially outward, but the electric field at the surface of a flat-tip emitter is parallel to the beam axis. Moreover, the useful number of CNTs on a flat surface is higher than that on a sharp surface. Consequently, an electron beam with a smaller diameter and a higher beam current can be obtained.

One problem that must be solved in the flat-tip CNT emitters is to prepare uniform CNTs on a small metal tip. Particularly, CNTs tend to be attached to the side surface of a metal tip because of the small geometry of the metal tip, as shown in the field-emission scanning electron microscope (FESEM) image of Figure 1(a). These CNTs attached to the side surface also act as electron emitters but badly affect the operation of an X-ray tube. Figure 1(b) displays the trajectories of electrons emitted at different positions of a flat emitter. The calculated was carried out using the EGN2 code [28]. In the calculation, a diode type composed of a flat-tip cathode emitter, a focusing electrode, and an anode was employed. The diameter of the emitter is $0.8 \mathrm{~mm}$, and the emitter is inserted inside a focusing electrode. If there is no focusing electrode, the electron beam that is produced from an emitter is dramatically diverged. The distance between the emitter and the anode is $13 \mathrm{~mm}$, and the applied voltage between the emitter and the anode is $50 \mathrm{kV}$. As shown in Figure 1(b), electrons emitted from a flat surface of the tip do not spread so much (electrons (1) and (2) in Figure 1(b)). An electron generated from the outermost position of a flat surface (electron (2. $0.4 \mathrm{~mm}$ far from the center of the tip) reaches the anode by $1.36 \mathrm{~mm}$ apart from the center. On the other hand, the electrons generated from the side surface of the tip diverge seriously even though a focusing electrode strongly prevents the divergence. An electron generated at $0.3 \mathrm{~mm}$ apart from the edge of the flat surface reaches the anode by $2.63 \mathrm{~mm}$ away from the center (electron (5). This was also experimentally verified. A diode gun as shown in Figure 1(a) was fabricated: a CNT tip emitter shown in Figure 1(a) was used for the electron emission. A phosphorous screen was installed at the anode position to measure the beam diameter at the anode position. Electrons were emitted from the CNT emitters through field emission and arrived at the phosphorous screen. The diameter of the electron beam at the phosphorous screen was $\sim 5.5 \mathrm{~mm}$. Due to the diverged electrons, the inner diameter of an X-ray tube cannot be reduced. An electrically insulating material should be used between the focusing electrode and the anode. An insulator with a smaller diameter must be used for a miniaturized X-ray tube. However, the diverged electrons can hit the insulator. This leads to the electrical charge builds upon the insulator and finally high voltage breakdown can occur. This prevents a stable operation of an $\mathrm{X}$-ray tube. Consequently, if CNTs are coated on a side plane of a tip, the radial size of an X-ray tube cannot be decreased below a certain diameter because electrons generated from the side plane can induce an unstable operation.

For the realization of a smaller miniaturized X-ray tube, a method to develop CNT tip emitters without CNTs coated on the side plane of a tip was developed (Figure 2). At first, a CNT solution was prepared: the solution is composed of a 4 w\% multiwalled CNTs (CM-95; Hanwha Nanotech Inc.) and $2 \mathrm{w} \%$ silver nanoparticles (NPs) (DGH; Advanced Nano Products Co., Ltd.) in a dichlorobenzene solvent. A $1 \mu \mathrm{L}$ drop of the solution was carefully attached to the flat surface of a tungsten (W) wire. The end surface of the $\mathrm{W}$ wire was polished, and its diameter was $0.8 \mathrm{~mm}$ (Figure 2(a)). The dropped solution keeps a hemispherical morphology on the $\mathrm{W}$ surface because of a surface tension (Figure 2(b)). The solution was completely dried at ambient condition, which removes dichlorobenzene from the solution while leaving CNTs and Ag NPs on the tip surface. Subsequently, the tip with the CNTs and Ag NPs was thermally annealed at $800^{\circ} \mathrm{C}$ for $2 \mathrm{~h}$ under vacuum. The annealing process melts 


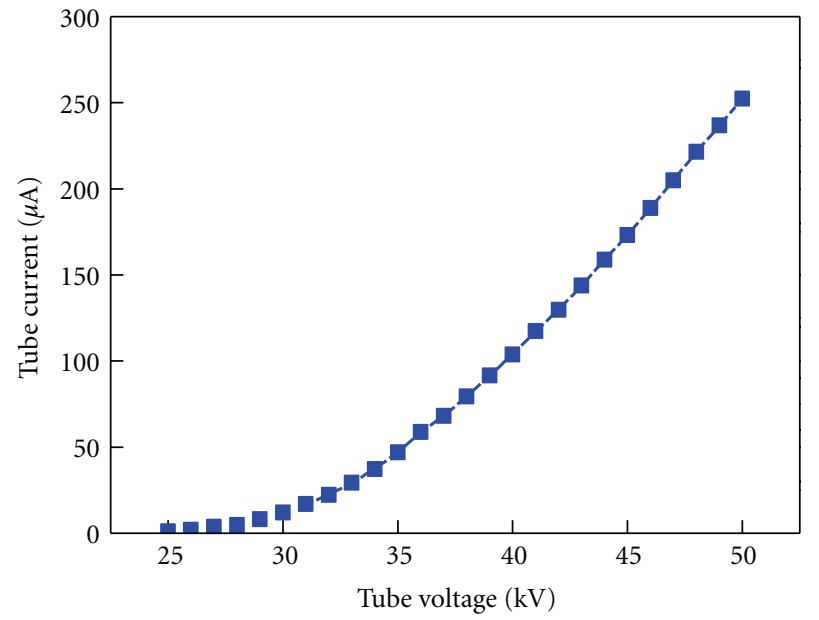

(a)

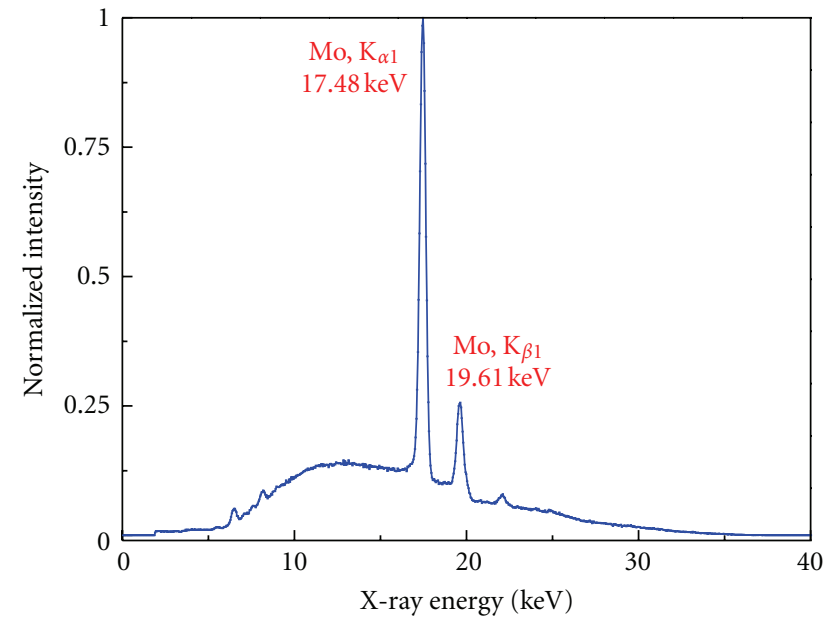

(b)

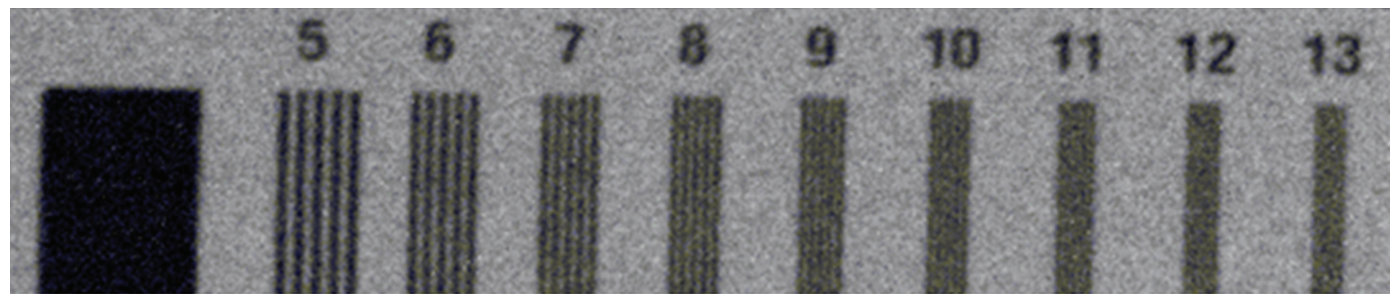

(c)

Figure 5: (a) Current-voltage behavior of the miniaturized X-ray tube. (b) Energy spectrum of the X-rays produced from the miniaturized $\mathrm{X}$-ray tube. The spectrum is normalized by the highest peak of $17.48 \mathrm{keV} \mathrm{Mo} \mathrm{K}_{\alpha 1}$ characteristics X-ray. (c) A radiograph of a line pair phantom.

Ag NPs to form Ag film on the W surface. This Ag film acts as an adhesive to strongly bind CNTs to the W surface. If the amount of the Ag NPs is properly chosen, one end of a CNT is emerged in the melted Ag film and the other end is exposed to the surface. An FESEM image displays the fabricated CNT tip emitter: CNTs are well attached to a flat W tip surface, and no CNTs are coated on the side plane of the tip (Figure 2(c)). The electron emission result using the fabricated CNT emitters shows that the diameter of an electron beam reaching at the anode was $\sim 2.5 \mathrm{~mm}$ (Figure 2(d)), which was much decreased compared to Figure 1.

The emission property of the fabricated CNT tip emitter was characterized using a diode geometry. The same focusing electrode as shown in Figure 1 was used for the characterization. The cathode-anode distance was $1.3 \mathrm{~mm}$. Figure 3 shows the measured current density-electric field profile of the emitter. The profile follows the Fowler-Nordheim (F-N) equation very well: a linear relationship between $\ln \left(J / E^{2}\right)$ and $1 / E$ was observed as shown in the inset of Figure 3. The threshold electric field corresponding to an emission current density of $10 \mathrm{~mA} / \mathrm{cm}^{2}$ was $1.15 \mathrm{~V} / \mu \mathrm{m}$. The field emission enhancement factor derived from the F-N plot was approximately 12,050 . These results indicate that the flat-tip CNT emitter exhibits a comparatively good field-emission performance.
In order to investigate the real device performance of the flat-tip CNT emitters, a miniaturized X-ray tube was fabricated using the CNT emitters. The schematic diagram of the miniaturized X-ray tube is shown in Figure 4. The X-ray tube consists of a flat-tip CNT emitter, a focusing electrode, and an X-ray target. The X-ray target acts as an anode. An alumina ceramic tube was used for an electrical insulator between the focusing electrode and the X-ray target. The inner diameter of the alumina tube was $5 \mathrm{~mm}$, the outer diameter of the tube was $7 \mathrm{~mm}$, and the total length of the $\mathrm{X}$-ray tube was $40 \mathrm{~mm}$. The X-ray target has a simple planar shape, and the target was prepared by coating molybdenum (Mo) on a thin beryllium X-ray window. All of the parts were vacuum tightly brazed in a vacuum furnace, and a getter was used to sustain a vacuum inside the X-ray tube. Consequently, the X-ray tube can be operated without an external vacuum pump. Figure 5(a) displays the measured current-voltage curve of the miniaturized X-ray tube. The $\mathrm{X}$-ray tube could be stably operated up to $50 \mathrm{kV}$ without any voltage breakdown after a short voltage conditioning [29]. The electron current reaching the X-ray target at $50 \mathrm{kV}$ was $213 \mu \mathrm{A}$. Figure 5 (b) shows the energy spectrum of the X-rays generated from the miniaturized X-ray tube. The energy spectrum was measured at $40 \mathrm{keV}$ with an $\mathrm{X}$ ray spectrometer (model: Amptek XR-100T-CdTe) that was $150 \mathrm{~cm}$ away from the X-ray target. In addition to the 
broad bremsstrahlung X-rays, Mo characteristic X-rays of $\mathrm{K}_{\alpha 1}$ at $17.48 \mathrm{keV}$ and $\mathrm{K}_{\beta 1}$ at $19.61 \mathrm{keV}$ were clearly observed. Figure 5(c) shows a radiograph of a line pair phantom that was achieved by the miniaturized X-ray tube and a CMOS 197 photodiode array detector (Vatech Xmaru0505CF, pixel pitch $24 \mu \mathrm{m})$. Up to 10 line pairs/mm was clearly resolved.

In summary, we fabricated flat-tip CNT emitters for miniaturized X-ray tubes and successfully demonstrated the operation of a miniaturized X-ray tube with the inner diameter of $5 \mathrm{~mm}$. The tip CNT emitter was prepared by coating CNTs on a flat surface of a W metal tip using Ag nanoparticles as an adhesive. The CNT emitters exhibit good field emission properties, and the beam divergence was minimized. We believe that flat-tip CNT emitters are very useful to realize smaller miniaturized X-ray tubes and highbrightness microfocus X-ray tubes.

\section{Acknowledgments}

This study was supported by the National Research Foundation of Korea (NRF) Grant funded by the Korea Government (MEST) (no. 2012-0005946) and the R\&D Program of MKE/KEIT (10035553).

\section{References}

[1] J. Kong, N. R. Franklin, C. Zhou et al., "Nanotube molecular wires as chemical sensors," Science, vol. 287, no. 5453, pp. 622 $625,2000$.

[2] Q. H. Wang, A. A. Setlur, J. M. Lauerhaas, J. Y. Dai, E. W. Seelig, and R. P. H. Chang, "A nanotube-based field-emission flat panel display," Applied Physics Letters, vol. 72, no. 22, pp. 2912-2913, 1998.

[3] R. G. Ding, G. Q. Lu, Z. F. Yan, and M. A. Wilson, "Recent advances in the preparation and utilization of carbon nanotubes for hydrogen storage," Journal of Nanoscience and Nanotechnology, vol. 1, no. 1, pp. 7-29, 2001.

[4] Y. Qin, M. Hu, H. Li, Z. Zhang, and Q. Zou, "Preparation and field emission properties of carbon nanotubes cold cathode using melting Ag nano-particles as binder," Applied Surface Science, vol. 253, no. 8, pp. 4021-4024, 2007.

[5] L. Wang, Z. Sun, T. Chen, and W. Que, "Growth temperature effect on field emission properties of printable carbon nanotubes cathode," Solid-State Electronics, vol. 50, no. 5, pp. 800804, 2006.

[6] J. L. Kwo, M. Yokoyama, W. C. Wang, F. Y. Chuang, and I. N. Lin, "Characteristics of flat panel display using carbon nanotube as electro emitters," Diamond Related Materials, vol. 9, no. 3-6, pp. 1270-1274, 2000.

[7] C. Niu, E. K. Sichel, R. Hoch, D. Moy, and H. Tennent, "High power electrochemical capacitors based on carbon nanotube electrodes," Applied Physics Letters, vol. 70, no. 11, pp. 14801482, 1997.

[8] W. A. de Heer, A. Chatelain, and D. Ugarte, "A carbon nanotube field-emission electron source," Science, vol. 270, no. 5239, pp. 1179-1180, 1995.

[9] S. Fan, M. G. Chapline, N. R. Franklin, T. W. Tombler, A. M. Cassell, and H. Dai, "Self-oriented regular arrays of carbon nanotubes and their field emission properties," Science, vol. 283, no. 5401, pp. 512-514, 1999.
[10] X. Xu and G. R. Brandes, "A method for fabricating large-area, patterned, carbon nanotube field emitters," Applied Physics Letters, vol. 74, no. 17, pp. 2549-2551, 1999.

[11] Z. F. Ren and Z. P. Huang, "Synthesis of large arrays of wellaligned carbon nanotubes on glass," Science, vol. 282, no. 5391, pp. 1105-1107, 1998.

[12] G. Gutman, E. Strumban, E. Sozontov, and K. Jenrow, "X-ray scalpel-a new device for targeted $\mathrm{X}$-ray brachytherapy and stereotactic radiosurgery," Physics in Medicine and Biology, vol. 52, no. 6, pp. 1757-1770, 2007.

[13] A. Dickler, "Xoft Axxent electronic brachytherapy-a new device for delivering brachytherapy to the breast," Nature Reviews Clinical Oncology, vol. 6, no. 6, pp. 138-142, 2009.

[14] L. N. Koppel and J. R. Marshall, "A miniature metal-ceramic Xray source for spacecraft instrumentation," Review of Scientific Instruments, vol. 69, no. 4, pp. 1893-1897, 1998.

[15] F. Schneider, H. Fuchs, F. Lorenz et al., "A novel device for intravaginal electronic brachytherapy," International Journal of Radiation Oncology Biology Physics, vol. 74, no. 4, pp. 12981305, 2009.

[16] M. J. Rivard, S. D. Davis, L. A. DeWerd, T. W. Rusch, and S. Axelrod, "Calculated and measured brachytherapy dosimetry parameters in water for the Xoft Axxent X-Ray Source: an electronic brachytherapy source," Medical Physics, vol. 33, no. 11, pp. 4020-4032, 2006.

[17] J. C. Yanch and K. J. Harte, "Monte Carlo simulation of a miniature, radiosurgery $\mathrm{x}$-ray tube using the ITS 3.0 coupled electron-photon transport code," Medical Physics, vol. 23, no. 9, pp. 1551-1558, 1996.

[18] P. Lovoi and J. F. Asmus, "An X-Ray microprobe for InSitu stone and wood characterization," in Proceedings of the Lasers in the Conservation of Artworks, vol. 100, pp. 353-356, Springer, Berlin, Germany, 2005.

[19] S. H. Heo, A. Ihsan, and S. O. Cho, "Transmission-type microfocus x-ray tube using carbon nanotube field emitters," Applied Physics Letters, vol. 90, no. 18, Article ID 183109, 2007.

[20] Y. Sakai, A. Haga, S. Sugita et al., "Electron gun using carbonnanofiber field emitter," Review of Scientific Instruments, vol. 78, no. 1, Article ID 013305, 2007.

[21] Y. Chen, D. T. Shaw, and L. Guo, "Field emission of different oriented carbon nanotubes," Applied Physics Letters, vol. 76, no. 17, pp. 2469-2471, 2000.

[22] S. K. Srivastava, V. D. Vankar, and V. Kumar, "Excellent field emission properties of short conical carbon nanotubes prepared by microwave plasma enhanced CVD process," Nanoscale Research Letters, vol. 3, no. 1, pp. 25-30, 2008.

[23] B. Gao, G. Z. Yue, Q. Qiu et al., "Fabrication and electron field emission properties of carbon nanotube films by electrophoretic deposition," Advanced Materials, vol. 13, no. 23, pp. 1770-1773, 2001.

[24] J. M. Bonard, C. Kinke, K. A. Dean, and B. F. Coll, "Degradation and failure of carbon nanotube field emitters," Physical Review B, vol. 67, no. 11, pp. 115406-115415, 2003.

[25] J. C. She, N. S. Xu, S. Z. Deng et al., "Vacuum breakdown of carbon-nanotube field emitters on a silicon tip," Applied Physics Letters, vol. 83, no. 13, pp. 2671-2673, 2003.

[26] X. H. Liang, S. Z. Deng, N. S. Xu, Jun Chen, N. Y. Huang, and J. C. She, "Noncatastrophic and catastrophic vacuum breakdowns of carbon nanotube film under direct current conditions," Journal of Applied Physics, vol. 101, no. 6, Article ID 063309, 2007.

[27] N. Y. Huang, J. C. She, J. Chen et al., "Mechanism responsible for initiating carbon nanotube vacuum breakdown," Physical Review Letters, vol. 93, no. 7, Article ID 075501, 2004. 
[28] W. B. Herrmannsfeldt and G. A. Herrmannsfeldt, EGN Electron Optics Program, SLAC, Stanford, Calif, USA, 1993.

[29] J. L. Kwo, C. C. Tsou, M. Yokoyama et al., "Field emission characteristics of carbon nanotube emitters synthesized by arc discharge," Journal of Vacuum Science and Technology B, vol. 19, no. 1, pp. 23-26, 2001. 

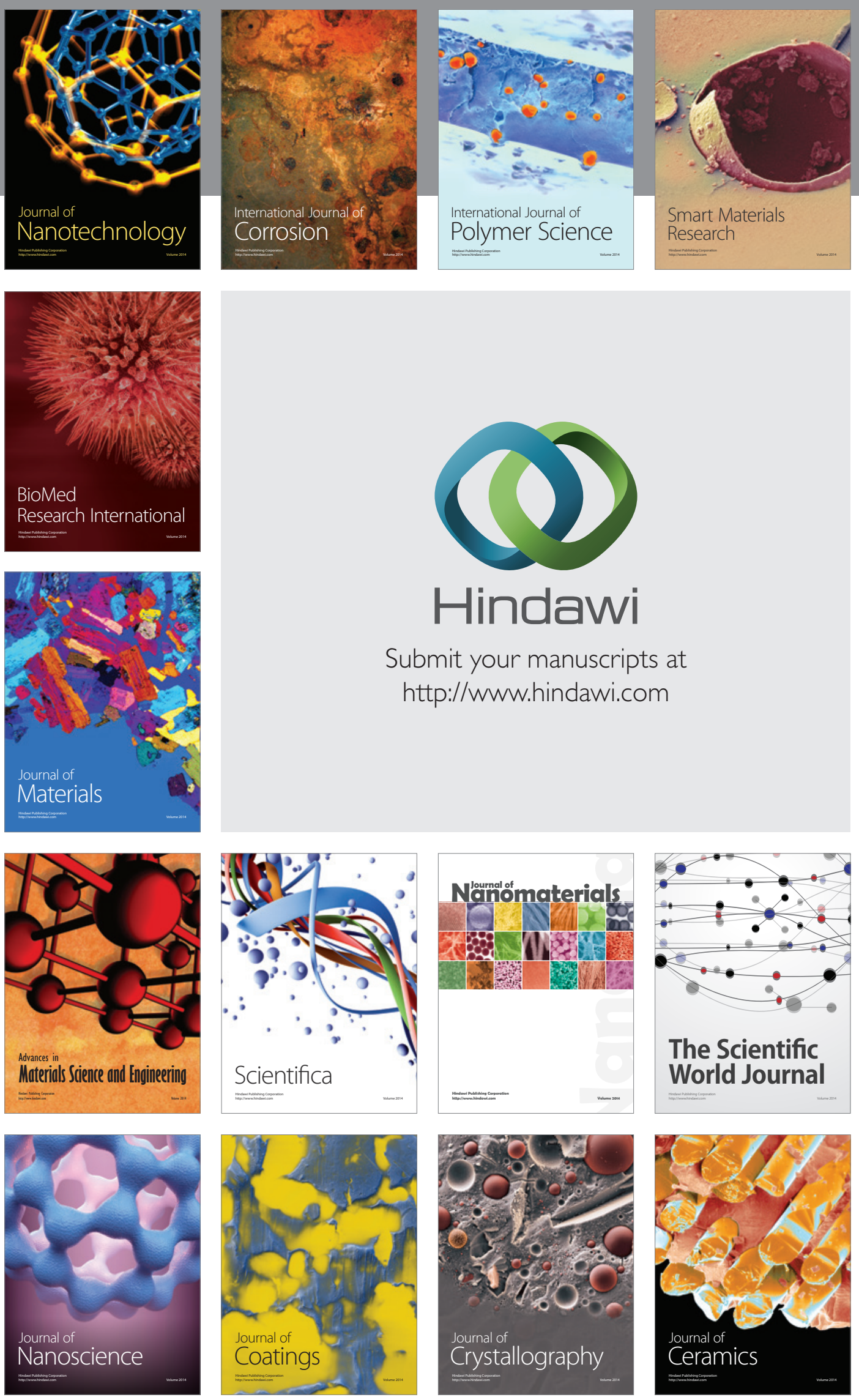

The Scientific World Journal

Submit your manuscripts at

http://www.hindawi.com

\section{World Journal}

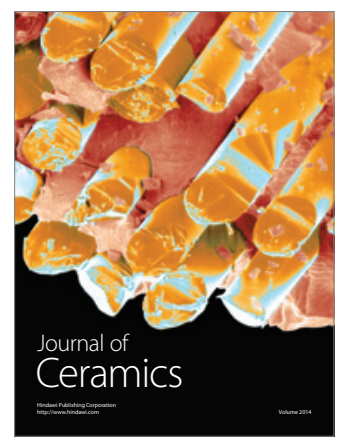

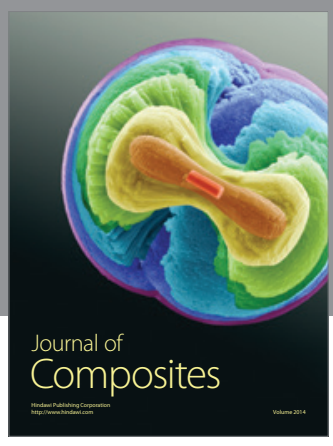
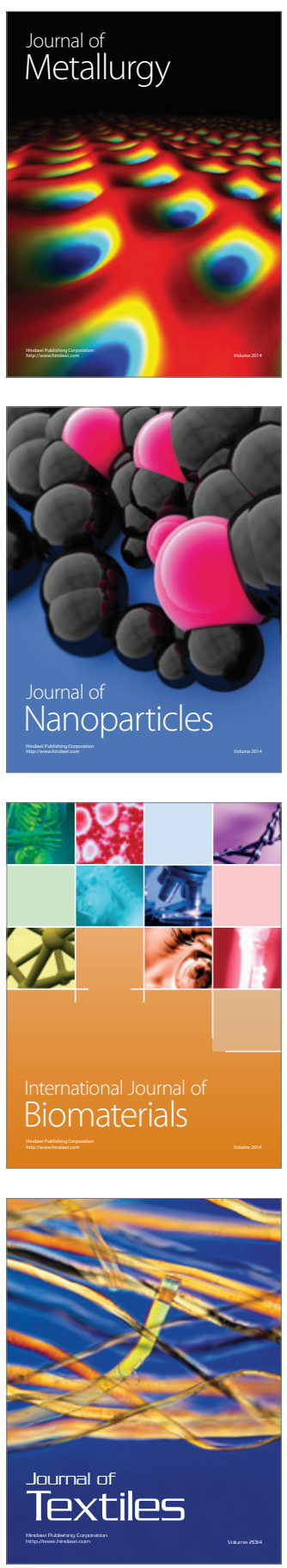